\title{
Prevalence and Clinical Characteristics of Hidradenitis Suppurativa Phenotypes in a Large Dutch Cohort
}

\author{
Koen Dudink Pim Aarts Christine B. Ardon Allard R.J.V. Vossen \\ Sterre B.L. Koster Jonathan F. Van den Bosch Errol P. Prens Hessel H. van der Zee \\ Department of Dermatology, Erasmus MC, University Medical Center Rotterdam, Rotterdam, The Netherlands
}

Dear Editor,

Hidradenitis suppurativa (HS) is a chronic, recurrent, debilitating inflammatory skin disease. It has a heterogeneous clinical presentation regardless of disease severity [1]. Therefore, different phenotypes are thought to exist which might differ in their pathogenesis and prognosis and which will likely benefit from different treatment modalities.

Based on clinical experience, a set of six phenotypes has been proposed in this journal: regular, frictional furunculoid, scarring folliculitis, conglobata, ectopic and syndromic [2]. However, our continued clinical experience suggested that the ectopic and syndromic types do not have specific clinical features and could be categorized as one of the other phenotypes. Here, we present the prevalence and patient characteristics of these phenotypes in a population of 935 Dutch HS patients participating in our HS registry at the Department of Dermatology of the Erasmus University Medical Center and its affiliated DermaHaven. All patients included in the study were diagnosed with HS according to the criteria of the European S1 guideline [3]. To help the phenotype designation in daily practice, we included a flowchart (Fig. 1) and prototypical clinical pictures of the phenotypes (available at www.karger.com/doi/10.1159/000518965). The need for ethical approval was waived by the Medical Research Eth-

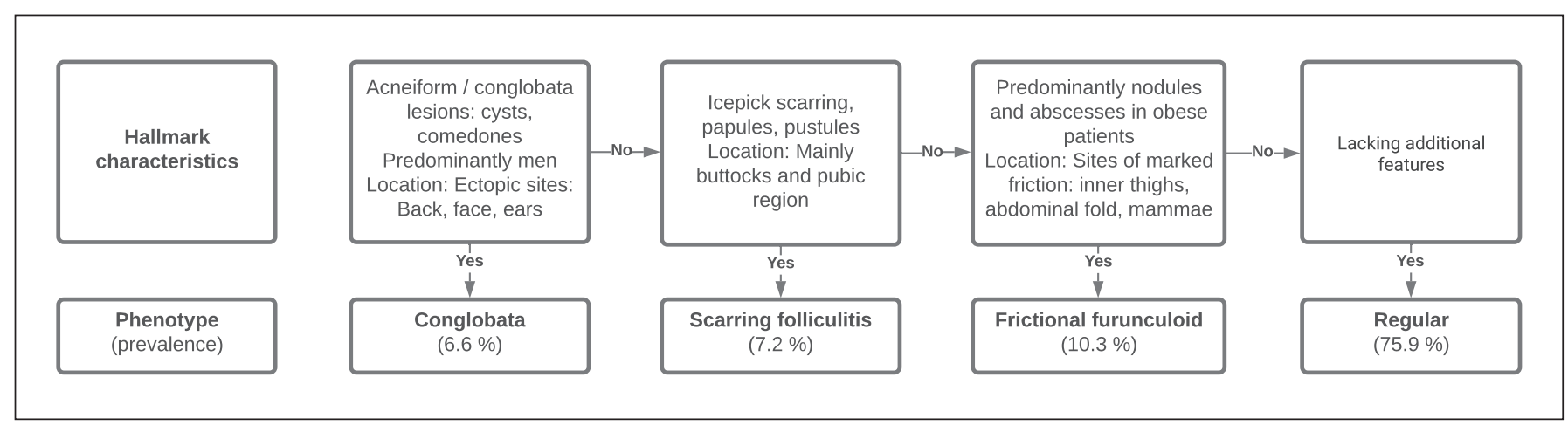

Fig. 1. Flowchart to determine HS phenotypes in patients with diagnosed HS.

\section{karger@karger.com} www.karger.com/drm

Karger $\stackrel{\text { ' }}{5}$

BOPEN ACCESS
(C) 2021 The Author(s)

Published by S. Karger AG, Basel

This is an Open Access article licensed under the Creative Commons Attribution-NonCommercial-4.0 International License (CC BY-NC) (http://www.karger.com/Services/OpenAccessLicense), applicable to the online version of the article only. Usage and distribution for commercial purposes requires written permission.
Correspondence to:

Koen Dudink, k.dudink@erasmusmc.nl 
Table 1. Patient characteristics per phenotype

\begin{tabular}{|c|c|c|c|c|c|}
\hline & All patients & Regular & $\begin{array}{l}\text { Frictional } \\
\text { furunculoid }\end{array}$ & $\begin{array}{l}\text { Scarring } \\
\text { folliculitis }\end{array}$ & Conglobata \\
\hline Patients, $n$ & 935 (100\%) & 710 (75.9\%) & $96(10.3 \%)$ & $67(7.2 \%)$ & $62(6.6 \%)$ \\
\hline \multicolumn{6}{|l|}{ Gender, $n$} \\
\hline Female & $656(70.2 \%)$ & $508(71.5 \%)$ & $76(79.2 \%)$ & $54(80.6 \%)$ & $18(29.0 \%)$ \\
\hline Male & 279 (29.8\%) & 202 (28.5\%) & $20(20.8 \%)$ & $13(19.4 \%)$ & $44(71.0 \%)$ \\
\hline Missing & 0 & 0 & 0 & 0 & 0 \\
\hline \multicolumn{6}{|l|}{ Age of onset, years } \\
\hline Median & 19.0 & 20.0 & 17.5 & 17.0 & 16.0 \\
\hline IQR (Q1, Q3) & $15.0,27.0$ & $15.0,28.0$ & $14.0,27.0$ & $14.0,22.0$ & $14.0,19.0$ \\
\hline Missing & 195 (20.9\%) & $150(21.1 \%)$ & $22(22.9 \%)$ & $12(17.9 \%)$ & $11(17.7 \%)$ \\
\hline \multicolumn{6}{|l|}{ Family history, $n$} \\
\hline Yes (1st/2nd) & 291 (51.2\%) & $226(52.3 \%)$ & 30 (52.6\%) & $18(43.9 \%)$ & $17(44.7 \%)$ \\
\hline No & 277 (48.8\%) & 206 (47.7\%) & 27 (47.4\%) & $23(56.1 \%)$ & $21(55.3 \%)$ \\
\hline Missing/unknown & 367 (39.3\%) & 278 (39.2\%) & 39 (40.6\%) & $26(38.8 \%)$ & $24(38.7 \%)$ \\
\hline \multicolumn{6}{|l|}{$B M I$} \\
\hline Median & 27.76 & 27.15 & 33.53 & 29.51 & 26.25 \\
\hline IQR (Q1, Q3) & $24.34,31.97$ & $23.73,31.28$ & $29.08,37.33$ & $26.59,32.42$ & $23.22,29.65$ \\
\hline Missing & $123(13.1 \%)$ & $100(14.1 \%)$ & $6(6.3 \%)$ & $4(6 \%)$ & $13(21 \%)$ \\
\hline \multicolumn{6}{|l|}{ Smoking status, $n$} \\
\hline Yes/Quit & $556(73.0 \%)$ & 403 (70.3\%) & $56(75.7 \%)$ & $52(86.7 \%)$ & $45(81.8 \%)$ \\
\hline No & $206(27.0 \%)$ & $170(29.7 \%)$ & $18(24.3 \%)$ & $8(13.3 \%)$ & $10(18.2 \%)$ \\
\hline Missing & 173 (18.5\%) & 137 (19.3\%) & $22(22.9 \%)$ & $7(10.4 \%)$ & $7(11.3 \%)$ \\
\hline \multicolumn{6}{|l|}{ IHS4 } \\
\hline Median & 3.0 & 3.0 & 4.0 & 3.0 & 5.0 \\
\hline IQR (Q1, Q3) & $1.0,8.0$ & $1.0,7.0$ & $1.0,12.0$ & $0.0,7.0$ & $1.0,14.25$ \\
\hline Missing & $32(3.4 \%)$ & $23(3.2 \%)$ & $1(1 \%)$ & $4(6 \%)$ & $4(6.5 \%)$ \\
\hline \multicolumn{6}{|l|}{ Hurley stage, $n$} \\
\hline I & 508 (54.9\%) & $375(53.2 \%)$ & $64(68.1 \%)$ & $44(67.7 \%)$ & $25(41.0 \%)$ \\
\hline II & $350(37.8 \%)$ & $284(40.3 \%)$ & $20(21.3 \%)$ & $20(30.8 \%)$ & $26(42.6 \%)$ \\
\hline III & $67(7.3 \%)$ & $46(6.5 \%)$ & $10(10.6 \%)$ & $1(1.5 \%)$ & $10(16.4 \%)$ \\
\hline Missing & $10(1.1 \%)$ & $5(0.7 \%)$ & $2(2.1 \%)$ & $2(2 \%)$ & $1(1.5 \%)$ \\
\hline \multicolumn{6}{|l|}{ Comorbidities } \\
\hline Crohn's disease & $23(3.0 \%)$ & $20(3.5 \%)$ & $1(1.3 \%)$ & $2(3.5 \%)$ & $0(0 \%)$ \\
\hline Ulcerative colitis & 11 (1.4\%) & $9(1.6 \%)$ & $1(1.3 \%)$ & $1(1.8 \%)$ & $0(0 \%)$ \\
\hline SpA & $9(1.2 \%)$ & $3(0.5 \%)$ & $2(2.5 \%)$ & $1(1.8 \%)$ & $3(5.6 \%)$ \\
\hline RA & $27(3.5 \%)$ & $19(3.3 \%)$ & $3(3.8 \%)$ & $2(3.5 \%)$ & $3(5.6 \%)$ \\
\hline Missing & $168(18.0 \%)$ & 134 (18.9\%) & $16(16.7 \%)$ & $10(14.9 \%)$ & $8(12.9 \%)$ \\
\hline
\end{tabular}

BMI, body mass index; IHS4, International Hidradenitis Suppurativa Severity Score System; SpA, spondyloarthritis; $R A$, rheumatoid arthritis; IQR, interquartile range; $Q$, quartile.

ics Committee of the Erasmus University Medical Center (MEC 2016-426).

After descriptive statistical analysis, several noticeable differences between phenotypes became apparent (Table 1). The regular type was the most common variant (75.9\%), followed by frictional furunculoid (10.3\%), scarring folliculitis $(7.2 \%)$ and the conglobata phenotype
(6.6\%). The conglobata variant was the only phenotype with a male predominance (71\%). All phenotypes with specific clinical characteristics (i.e., frictional furunculoid, scarring folliculitis and conglobata) tended to have an earlier age of onset (respective median ages of 17.5, 17 and 16 years) compared to the regular type (median age of 20 years). Patients with the frictional furunculoid type had the 
highest body mass index (median of 33.5 vs. 27.2 in the regular group). The distinct phenotypes also demonstrated a higher prevalence of smoking when compared to the regular type, most notably in the scarring folliculitis and conglobata variants ( 86.7 and 81.8 vs. $70.3 \%$ ). Patients with the conglobata phenotype tended to have more severe HS according to the International Hidradenitis Suppurativa Severity Score System and Hurley stage, this in contrast to the scarring folliculitis phenotype which yielded the mildest cases. Interestingly, a positive family history of HS did not differ between the proposed phenotypes. Concomitant auto-inflammatory diseases were reported in $9.1 \%$ (70 of 767) of the patients in the registry. The frequency of spondyloarthritis and rheumatoid arthritis was highest in the conglobata phenotype while inflammatory bowel disease was not reported in this phenotype.

A strength of this study is that these phenotypes are based on extensive clinical experience and not solely on analysis of a data set lacking important clinical parameters [4]. The clinical characteristics and phenotypes can be used in future research such as genome-wide association studies. Furthermore, linking the phenotype and genotype could pave the way for a more tailor-made approach for future HS treatment options.

\section{Key Message}

Hidradenitis suppurativa can be stratified in different distinct clinical phenotypes, each possibly warranting specific treatment.

\section{Statement of Ethics}

Written informed consent to use the photos for publication was obtained from each patient. The need for ethical approval was waived by the Medical Research Ethics Committee of the Erasmus University Medical Center (MEC 2016-426).

\section{Conflict of Interest Statement}

Koen Dudink reports no conflicts of interest. Pim Aarts reports no conflicts of interest. Christine B. Ardon reports no conflicts of interest. Allard R.J.V. Vossen reports no conflicts of interest. Sterre B.L. Koster reports no conflicts of interest. Jonathan F. van den Bosch reports no conflicts of interest. Errol P. Prens received honoraria from AbbVie, Amgen, Celgene, Janssen, Galderma, Novartis and Pfizer for participation as a speaker and serving on advisory boards and also received investigator-initiated grants (paid to the Erasmus MC) from AbbVie, AstraZeneca, Janssen and Pfizer. Hessel H. van der Zee received honoraria from AbbVie, Galderma, Novartis and InflaRX for participation as a speaker and serving on advisory boards.

\section{Funding Sources}

There are for this study no relevant funding sources to declare.

\section{Author Contributions}

All authors have significant contribution to conceptualizing, writing and editing this paper. They have agreed to designate Koen Dudink as the primary correspondent with the editorial office to review the edited typescript and proof, and to make decisions regarding release of information in the paper.

\section{References}

1 Sabat R, Jemec GBE, Matusiak Ł, Kimball AB, Prens E, Wolk K. Hidradenitis suppurativa. Nat Rev Dis Primers. 2020 Mar;6(1):18.

2 Van der Zee HH, Jemec GB. New insights into the diagnosis of hidradenitis suppurativa: clinical presentations and phenotypes. J Am Acad Dermatol. 2015 Nov;73(5 Suppl 1):S23-6.
3 Zouboulis CC, Desai N, Emtestam L, Hunger RE, Ioannides D, Juhász I, et al. European S1 guideline for the treatment of hidradenitis suppurativa/acne inversa. J Eur Acad Dermatol Venereol. 2015 Apr;29(4):619-44.
4 Van Straalen KR, Verhagen T, Horváth B, Ardon C, Vossen ARJV, Driessen R, et al. Poor interrater reliability of hidradenitis suppurativa phenotypes. J Am Acad Dermatol. 2018 Sep;79(3):577-8. 